\title{
Downregulation of the Escherichia coli guaB promoter by FIS
}

\author{
Seyyed I. Husnain and Mark S. Thomas \\ F Floor, School of Medicine and Biomedical Sciences, University of Sheffield, Beech Hill Road, \\ Sheffield S10 2RX, UK
}

Correspondence

Mark S. Thomas

m.s.thomas@sheffield.ac.uk

Received 20 January 2008

Revised 5 March 2008

Accepted 12 March 2008

\begin{abstract}
The Escherichia coli guaB promoter $\left(\mathrm{P}_{\text {guaB }}\right)$ regulates transcription of two genes, gua $B$ and gua $A$, that are required for the synthesis of guanosine $5^{\prime}$-monophosphate (GMP), a precursor for the synthesis of guanine nucleoside triphosphates. Transcription from $\mathrm{P}_{\text {gua }}$ increases as a function of increasing cellular growth rate, and this is referred to as growth rate-dependent control (GRDC). Here we investigated the role of the factor for inversion stimulation (FIS) in the regulation of this promoter. The results showed that there are three binding sites for FIS centred near positions $-11,+8$ and +29 relative to the guaB transcription start site. Binding of FIS to these sites results in repression of $\mathrm{P}_{\text {guaB }}$ in vitro but not in vivo. Deletion of the fis gene results in increased $\mathrm{P}_{\text {guaB }}$ activity in vivo, but GRDC of $\mathrm{P}_{\text {guaB }}$ is maintained.
\end{abstract}

\section{INTRODUCTION}

The Escherichia coli guaB promoter $\left(\mathrm{P}_{\text {guaB }}\right)$ regulates transcription of two genes, guaB and guaA, which together constitute the guaBA operon. The guaB and guaA genes encode inosine $5^{\prime}$-monophosphate (IMP) dehydrogenase and guanosine $5^{\prime}$-monophosphate (GMP) synthetase, respectively, and are required for the biosynthesis of GMP from the common purine nucleotide precursor, IMP (Mehra \& Drabble, 1981; Tiedeman \& Smith, 1984). $\mathrm{P}_{\text {guaB }}$ is regulated by the cAMP receptor protein (CRP) and a putative CRP binding site is centred near position -117.5 relative to the guaB transcription start site (Hutchings \& Drabble, 2000). Furthermore, transcription from $\mathrm{P}_{\text {guab }}$ is strongly enhanced by an UP element (Husnain \& Thomas, 2008). $\mathrm{P}_{\text {gua }}$ also contains a putative binding site for PurR that overlaps the core promoter region, and PurR downregulates expression of guaB (Meng et al., 1990; Davies \& Drabble, 1996). DnaA binds to a sequence overlapping the core promoter region and also downregulates transcription from $\mathrm{P}_{\text {guaB }}$ (Tesfa-Selase \& Drabble, 1996). It has also been shown that the rate of transcription from $\mathrm{P}_{\text {gua }}$ per unit cell mass increases as a function of increasing cellular growth rate (Davies \& Drabble, 1996; Husnain \& Thomas, 2008). This phenomenon is commonly referred to as growth ratedependent control (GRDC) (Gourse et al., 1996; Dennis et al., 2004). GRDC of $\mathrm{P}_{\text {guab }}$ requires the UP element and sequences located upstream of the UP element (Husnain \& Thomas, 2008).

The factor for inversion stimulation (FIS) regulates transcription by binding to highly degenerate 15 bp DNA

Abbreviations: CRP, cAMP receptor protein; EMSA, electromobility shift assay; FIS, factor for inversion stimulation; GRDC, growth ratedependent control; RNAP, RNA polymerase. sequences (Finkel \& Johnson, 1992; Ross et al., 1999). At some E. coli promoters, FIS activates transcription by contacting the C-terminal domain of the RNA polymerase (RNAP) $\alpha$ subunit ( $\alpha$ CTD) (Aiyar et al., 2002; McLeod et al., 2002). FIS can also promote transcription by decreasing the negative superhelicity of DNA (Travers et al., 2001). At other promoters, FIS downregulates promoter activity by binding to a site that overlaps or is located downstream from the RNAP binding site, or by forming a complex assembly with other nucleoid proteins (Gonzalez-Gil et al., 1998; Browning et al., 2000, 2004; Jackson et al., 2004). A previous study identified four putative binding sites for FIS that are located upstream of the $\mathrm{P}_{\text {gua }}$ core promoter region (Hutchings \& Drabble, 2000). The putative FIS binding sites are centred near positions $-77,-92,-109$ and -126 relative to the guaB transcription start, and were referred to as FIS sites I-IV, respectively (Fig. 1a). FIS contributes to GRDC of the thrU and $p d x A$ promoters, and is required for growth ratedependent synthesis of $4.5 \mathrm{~S}$ RNA, tRNA ${ }_{2}^{\text {Ser }}$ and tRNA ${ }_{2}^{\text {Thr }}$ (Emilsson \& Nilsson, 1995; Dong et al., 1996). Moreover, transcription from the fis promoter is coupled to cellular growth rate (Mallik et al., 2006). Cellular levels of FIS and FIS mRNA also change with the growth phase, and they increase dramatically upon entry into the mid-exponential growth phase (Appleman et al., 1998; Ali Azam et al., 1999; Mallik et al., 2006).

In this work, we investigated whether FIS plays a role in the regulation of $\mathrm{P}_{\text {guaB }}$. We show that the putative FIS binding sites located upstream of the $\mathrm{P}_{\text {gua }}$ core elements do not recruit FIS (Hutchings \& Drabble, 2000). Moreover, we demonstrate that FIS is recruited to three sites centred near $-11,+8$ and +29 relative to the guaB transcription start site, and all three sites are necessary for full FIS-mediated 
(a)

$$
\begin{array}{cccc}
-250 & -230 & -210 & -190 \\
\cdot & \cdot & \cdot & \cdot \\
\text { AGCTGGTTGCGTGAAATTAGAAATTTCGCCGCTGATCCAAACCTGTCCCATCTCATGCTCAAGCAGCAGACGAACCGT } \\
-170 & -150 & -130 & -110
\end{array}
$$

FIS 1

\begin{tabular}{|c|c|c|c|c|}
\hline & Location & Category & $\frac{\text { Protection }}{\underline{\text { by FIS }}}$ & $\begin{array}{l}\text { FIS site } \\
\text { designation }\end{array}$ \\
\hline $\begin{array}{l}\text { GcaagcaTtt TttgC } \\
\text { GgtcgagAtaTtgcC }\end{array}$ & $\begin{array}{l}-59 \text { to }-45 \\
+22 \text { to }+36\end{array}$ & 1 & $\begin{array}{l}- \\
+\end{array}$ & Site 3 \\
\hline $\begin{array}{l}\text { GatccaaAccTgtcC } \\
\text { Gcaatat } \mathbf{T t a} \text { TtaaC }\end{array}$ & $\begin{array}{l}-220 \text { to }-206 \\
+1 \text { to }+15\end{array}$ & 2 & $\begin{array}{l}- \\
+\end{array}$ & Site 2 \\
\hline 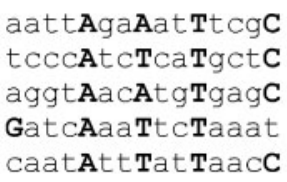 & $\begin{array}{l}-239 \text { to }-225 \\
-208 \text { to }-194 \\
-133 \text { to }-119 \\
-116 \text { to }-102 \\
+2 \text { to }+16\end{array}$ & $\underline{3}$ & $\begin{array}{l}- \\
- \\
- \\
- \\
+\end{array}$ & $\begin{array}{l}\text { Site IV } \\
\text { Site III } \\
\text { Site } 2^{\prime}\end{array}$ \\
\hline $\begin{array}{l}\text { GcaggttAttcagtC } \\
\text { GatagtaAccogCCC } \\
\text { GctctgtAtaatgcC }\end{array}$ & $\begin{array}{l}-99 \text { to }-85 \\
-84 \text { to }-70 \\
-18 \text { to }-4\end{array}$ & other sites & $\begin{array}{l}- \\
- \\
+\end{array}$ & $\begin{array}{l}\text { Site II } \\
\text { Site I } \\
\text { Site } 1\end{array}$ \\
\hline 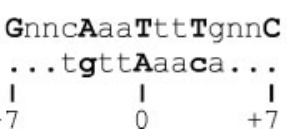 & & & & Consensus \\
\hline
\end{tabular}

FIS 2

FIS 3

(b)

repression. We also show that FIS is not required for GRDC of $\mathrm{P}_{\text {guab }}$.

\section{METHODS}

Strains and plasmids. All strains were derivatives of the E. coli K-12 strain VH1000. Each strain contained a chromosomally integrated transcriptional fusion of lac $Z$ to one of three $\mathrm{P}_{\text {gua }}$ derivatives: the full-length guaB promoter (i.e. strain VH1000G-253), extending from positions -253 to +36 relative to the $g u a B$ transcription start site $\left[\mathrm{P}_{\text {gua }}(-253\right.$ to +36$\left.)\right]$ (Husnain \& Thomas, 2008), the $\mathrm{P}_{\text {guaB }}(-253$ to +10$)$ promoter (i.e. strain VH1000G-25310, this work), which contains the same upstream end point as the full-length promoter but has a downstream end point at +10 , and the $\mathrm{P}_{\text {guas }}(-69$ to +36$)$ promoter (i.e. strain VH1000G-69, this work), which has the same downstream end point as the full-length promoter but has an upstream end point at position -69 relative to the $g u a B$ transcription start site. Fusions were carried on $\lambda$ prophage and were constructed using a system based on $\lambda$ imm21 (Simons et al., 1987; Rao et al., 1994). Strain VH1000G-253 $\Delta$ fis was made by introducing the 
Fig. 1. Identification of putative FIS sites at $P_{\text {guaB }}$ (a) Sequence of the guaB promoter from positions -253 to +40 relative to the guaB transcription start site. Putative FIS sites I-IV, FIS sites 1-3, a putative CRP binding site centred at position -117.5 and binding sites for PurR and DnaA are indicated (Hutchings \& Drabble, 2000). The core promoter elements ( -35 and -10 regions), UP element, and the initiating nucleotide are also shown, in bold. Apart from FIS sites I-IV, putative FIS sites that have been shown not to bind FIS in this work are not indicated. For clarity, FIS site 2' is not shown. (b) Candidate FIS binding sites were identified by comparing the consensus sequence for FIS (Ross et al., 1999; Shultzaberger et al., 2007) with $\mathrm{P}_{\text {guaB }}$ sequences located from positions -253 to +36 . The consensus sequence employed is indicated accordingly; alternative bases at each position of the consensus sequence are shown in the second line. Conserved bases at the five positions considered to be critical for FIS binding (positions $-7,-3,0,+3$ and +7 ) are emboldened, and the most frequently occurring base is shown in upper case. ' $n$ ' signifies any base. Candidate FIS sites are categorized according to their similarity to the consensus. Category 1 and 2 sites exhibit a 4/5 match at the critical positions, including positions +7 and -7 , which are most strongly conserved among FIS sites. However, at category 2 sites, an infrequently occurring base is present at position $-3,0$ or +3 (in the case of $\mathrm{P}_{\text {guaB }}$, such mismatches only occur at position -3). Category 3 sites also exhibit a $4 / 5$ match at the critical positions but the mismatched base occurs at position +7 or -7 . Other pertinent sites that do not fulfil the criteria for inclusion in categories 1-3 are shown as 'other sites'. FIS sites that were protected by FIS in DNase I footprinting are as indicated.

fis:: aadA allele from strain JCB38841 (Ball et al., 1992; Wu et al., 1998) into VH1000G-253 by P1 transduction; strain VH1000G- $69 \Delta$ fis was made by introducing the same allele into VH1000G-69. All plasmids contain $\mathrm{P}_{\text {guaB }}$ derivatives that were inserted as EcoRIHindIII fragments. Plasmids pBSG-253 and pBSG-133 are derivatives of pBluescript II KS containing the promoters $\mathrm{P}_{\text {guaB }}(-253$ to +36$)$ and $\mathrm{P}_{\text {gua }}(-133$ to +36$)$, respectively. pUCG-253 is a derivative of pUC19 containing $\mathrm{P}_{\text {guaB }}(-253$ to +36$)$. The plasmid pRLG770 has been described previously (Ross et al., 1990). pRLG770 derivatives containing promoters $\mathrm{P}_{\text {guaB }}(-253$ to +36$), \mathrm{P}_{\text {guaB }}(-133$ to +36$)$, $\mathrm{P}_{\text {gua }}(-59$ to +36$)$ and $\mathrm{P}_{\text {gua }}(-37$ to +36$)$ were constructed previously (Husnain \& Thomas, 2008). pRLG770 derivatives pRLG13321, pRLG-1331 and pRLG-25310 contain promoters $\mathrm{P}_{\text {gua }}(-133$ to +21$), \mathrm{P}_{\text {guaB }}(-133$ to +1$)$ and $\mathrm{P}_{\text {gua }}(-253$ to +10$)$, respectively.

DNase I footprinting. The EcoRI-XhoI DNA fragment in pBSG-253 was purified following electrophoresis in a $6 \%$ acrylamide gel (Meng et al., 2000), labelled at the downstream (XhoI) end with $\left[\gamma_{-}{ }^{32} \mathrm{P}\right] \mathrm{ATP}$ $\left[>7000 \mathrm{Ci}\left(2.59 \times 10^{14} \mathrm{~Bq}\right) \mathrm{mmol}^{-1}\right.$, MP Biomedicals] and subsequently purified according to a published procedure (Husnain \& Thomas, 2008). The EcoRI-XhoI fragment in pBSG-133 was labelled similarly at the upstream end. Labelled DNA fragment $(4 \mathrm{nM})$ was incubated at room temperature for $30 \mathrm{~min}$ in a volume of $20 \mu \mathrm{l}$ containing $20 \mathrm{mM}$ HEPES ( $\mathrm{pH} 8.0$ ), $5 \mathrm{mM} \mathrm{MgCl}_{2}, 50 \mathrm{mM}$ potassium glutamate, $1 \mathrm{mM}$ DTT, $20 \mu \mathrm{g} \mathrm{ml}^{-1}$ sonicated calf thymus DNA (GE Healthcare) and $5 \%(\mathrm{v} / \mathrm{v})$ glycerol, in the absence or presence of purified FIS protein. Purified FIS was a generous gift from T. Gaal and R. L. Gourse (University of Wisconsin-Madison). DNase I footprinting and DNA fragment separation were performed exactly as described previously (Husnain \& Thomas, 2008). Footprints were visualized using a FujiFilm FLA3000 phosphorimager.

Electromobility shift assay (EMSA). A DNA fragment containing $\mathrm{P}_{\text {guaB }}(-253$ to +36$)$ was amplified by PCR from pUCG-253, using primers pUC19(for) (5'-ACGTTGTAAAACGACGGCCAG-3') and pUC19(rev) (5'-GCGCGGATCCATGACCATGATTACGCCAAGCT$\left.3^{\prime}\right)$. A DNA fragment containing the $r r n B$ P1 promoter with FIS site I (positions -87 to +50 relative to the $\operatorname{rrnB} \mathrm{P} 1$ transcription start site) and an $r r n B$ P1 promoter derivative that did not contain a FIS site (positions -37 to +52 relative to the $\mathrm{rrnB} \mathrm{P} 1$ transcription start site, and containing non- $r r n B P 1$ sequences upstream to position -92) were PCR amplified from plasmids pRLG1616 and pRLG4720, respectively, using a forward primer with the sequence $5^{\prime}$-GTATCACGAGGCCCT-3' and reverse primer RLG1620 (5'-GCGCTACGGCGTTTCACTTC-3'), both of which are vector-specific (Newlands et al., 1991; Ross et al., 1998; Meng et al., 2001). PCR products were digested with HindIII, and purified following electrophoresis in a $6 \%$ acrylamide gel (Meng et al., 2000). Fragments were labelled at the
HindIII end using $\left[\alpha_{-}{ }^{32} \mathrm{P}\right] \mathrm{dATP}\left[3000 \mathrm{Ci}\left(1.11 \times 10^{14} \mathrm{~Bq}\right) \mathrm{mmol}^{-1}\right.$, MP Biomedicals] and DNA polymerase I Klenow fragment. Labelled DNA (final concentration $0.4 \mathrm{nM}$ ) was incubated at room temperature for $30 \mathrm{~min}$ in a volume of $10 \mu$ l containing $20 \mathrm{mM}$ HEPES ( $\mathrm{pH} 8.0$ ), $5 \mathrm{mM} \mathrm{MgCl}_{2}, 50 \mathrm{mM}$ potassium glutamate, $1 \mathrm{mM}$ DTT, $10 \%(\mathrm{v} / \mathrm{v})$ glycerol and $20 \mu \mathrm{g} \mathrm{ml}^{-1}$ sonicated calf thymus DNA (GE Healthcare), in the absence or presence of different concentrations of FIS. Samples were loaded (under tension) onto a $6 \%$ acrylamide gel (37.5: 1 acrylamide: bis acrylamide) containing $7.5 \%(\mathrm{v} / \mathrm{v})$ glycerol while running at $\sim 15 \mathrm{~V} \mathrm{~cm}^{-1}$, and gels were run for $\sim 1 \mathrm{~h}$ at $4{ }^{\circ} \mathrm{C}$. Radiolabelled DNA was visualized using a FujiFilm FLA3000 phosphorimager.

Measurement of transcription in vitro. Multiple-round transcription reactions were performed as described previously, using supercoiled pRLG770 derivatives containing $\mathrm{P}_{\text {gua }}$ fragments (Husnain \& Thomas, 2008). As a control, transcription was also measured from an rrnB P1 promoter derivative that did not contain any FIS sites (plasmid pRLG4238; Estrem et al., 1998). FIS (250 nM) was incubated with DNA in reaction buffer at room temperature for $30 \mathrm{~min}$. Transcription was initiated at $30{ }^{\circ} \mathrm{C}$ with $10 \mathrm{nM} \mathrm{E}$. coli RNAP holoenzyme (Epicentre), and reactions were allowed to proceed for $20 \mathrm{~min}$.

Measurement of transcription in vivo. Strains containing a chromosomally integrated $\mathrm{P}_{\text {guaB }}$-lac $Z$ transcriptional fusion were employed in the measurement of promoter activity in vivo. Cells were inoculated from dense starter cultures into media that supported different cellular growth rates, as described previously (Husnain \& Thomas, 2008). The $\beta$-galactosidase activity was determined following disruption of cells by sonication (Miller, 1972). To measure promoter activity at different stages of the growth cycle, cells were grown overnight in M9 minimal medium with $0.4 \%(w / v)$ glucose, $0.8 \%(\mathrm{w} / \mathrm{v})$ Casamino acids and $5 \mu \mathrm{g}$ thiamine $\mathrm{ml}^{-1}$, and inoculated into fresh medium to an $\mathrm{OD}_{600}$ of $\sim 0.01$. Growth was monitored at $\mathrm{OD}_{600}$, and the $\beta$-galactosidase activity was measured at different points on the growth curve after cells were permeabilized with chloroform-SDS (Miller, 1972).

\section{RESULTS}

\section{Identification of putative FIS sites at $\mathbf{P}_{\text {gua }}$}

The $15 \mathrm{bp}$ consensus sequence for FIS [ $5^{\prime}-\mathrm{Gnn}(\mathrm{c} / \mathrm{t})(\underline{\mathrm{A} / \mathrm{g}})$ $\left.(\mathrm{a} / \mathrm{t})(\mathrm{a} / \mathrm{t})(\underline{\mathrm{T} / \mathrm{A}})(\mathrm{t} / \mathrm{a})(\mathrm{t} / \mathrm{a})(\underline{\mathrm{T} / \mathrm{c}})(\mathrm{g} / \mathrm{a}) \mathrm{nnC}-\mathrm{3}^{\prime}\right]$ contains five highly conserved positions (underlined) that are the most significant for the recruitment of FIS (Finkel \& Johnson, 
1992; Hengen et al., 1997; Ross et al., 1999; Shultzaberger et al., 2007; Shao et al., 2008). At each highly conserved position (hereafter referred to as a 'critical' position), an upper-case letter indicates the most strongly conserved base at that position, and a lower-case letter indicates a conserved base that is non-consensus. We employed the MatInspector program (Genomatix) to identify putative FIS sites at $\mathrm{P}_{\text {guaB }}$ that matched the consensus in at least four out of the five critical positions (Quandt et al., 1995). This was achieved by performing a sequence alignment of a modified consensus sequence (5'GnnnRnnWnnYnnnC-3', where $\mathrm{R}=\mathrm{A}$ or $\mathrm{G}$; $\mathrm{W}=\mathrm{A}$ or $\mathrm{T}$; $\mathrm{Y}=\mathrm{T}$ or $\mathrm{C} ; \mathrm{n}=$ any base) with $\mathrm{P}_{\text {guaB }} \mathrm{DNA}$ sequences located between positions -253 and +36 , and also with the reverse complement of this DNA sequence.

Using this approach, no sites were identified that contained the most highly conserved base at all five critical positions. However, we identified nine candidate FIS binding sites that contained the most highly conserved base at $4 / 5$ critical positions (Fig. 1b). All of these sites contained the consensus $\mathrm{A}$ or $\mathrm{T}$ base at the central position (position 0 ) and the conserved $\mathrm{T}$ residue at position +3 . These sequences were subdivided into three categories. Category 1 sites contain bases that match the consensus at $4 / 5$ critical positions, including the outer bases (positions -7 and +7 ) that are most strongly conserved among FIS sites and which are presumed to be bound by the D helices of FIS (Shultzaberger et al., 2007). The remaining critical position (position -3) contained the alternative purine base $\mathrm{G}$ that occurred less frequently at that position. Two candidate FIS sites were identified that fell into this category (Fig. 1b). Category 2 sites differ from category 1 sites in having a less frequently occurring $\mathrm{C}$ or $\mathrm{T}$ residue at position -3 . Two additional sites fell into this category. Category 3 sites also contain bases that match the consensus at $4 / 5$ critical positions. However, the mismatches occur at one of the highly conserved bases that are located at the outermost positions. Five sequences were classified as category 3 sites
(Fig. 1b). Two of them correspond to the previously identified putative FIS sites III and IV located upstream of $\mathrm{P}_{\text {guaB }}$ (Hutchings \& Drabble, 2000). Putative FIS sites I and II were not identified by this analysis as they harbour bases that match the consensus at only $3 / 5$ of the critical positions, although they do include non-consensus but frequently occurring bases at the remaining two critical positions (positions -3 and +3 ) (Fig. 1b).

\section{Analysis of FIS binding to $\mathbf{P}_{\text {gua }}$}

EMSA was employed to determine whether FIS can bind to a DNA fragment containing the guaB promoter. As a comparison, binding of FIS to the rrnB P1 promoter, which is known to bind FIS under physiological conditions, was also analysed. The rrnB P1 promoter fragment employed contained the promoter-proximal FIS site, i.e. FIS site I (Ross et al., 1990; Bokal et al., 1995). The minimum concentration of FIS required to observe FIS-DNA interactions at either $\mathrm{P}_{\text {guab }}(-253$ to +36$)$ or the $\mathrm{rrnB}$ P1 fragment by EMSA was $50 \mathrm{nM}$. Increasing the FIS concentration to $300 \mathrm{nM}$ resulted in the formation of three different complexes between FIS and $\mathrm{P}_{\text {guaB }}$ (Fig. 2). At this concentration of FIS, a larger fraction of the $r r n B$ P1 promoter fragment was bound by FIS, but there remained only a single FIS-DNA complex, and no FIS-DNA complexes were observed at an $\mathrm{rrnB}$ P1 promoter derivative that lacked a FIS site (Fig. 2). At a FIS concentration of $500 \mathrm{nM}$, an additional FIS-DNA complex was observed at both $\mathrm{P}_{\text {guaB }}$ and $r r n B P 1$ harbouring FIS site I. As a complex was also observed with the promoter fragment that did not contain a FIS site, it is likely that the additional FIS-DNA interactions observed at $500 \mathrm{nM}$ FIS are non-specific (Fig. 2). These results indicate that FIS binds to at least three sites at or near $\mathrm{P}_{\text {guaB }}$ under similar conditions to those in which FIS specifically binds to $\mathrm{rrnB}$ $\mathrm{P} 1$, and thereby suggest that FIS is likely to bind to these sites under physiological conditions.

[FIS] nM $0|2| 5|10| 50|100| 250|300| 500$

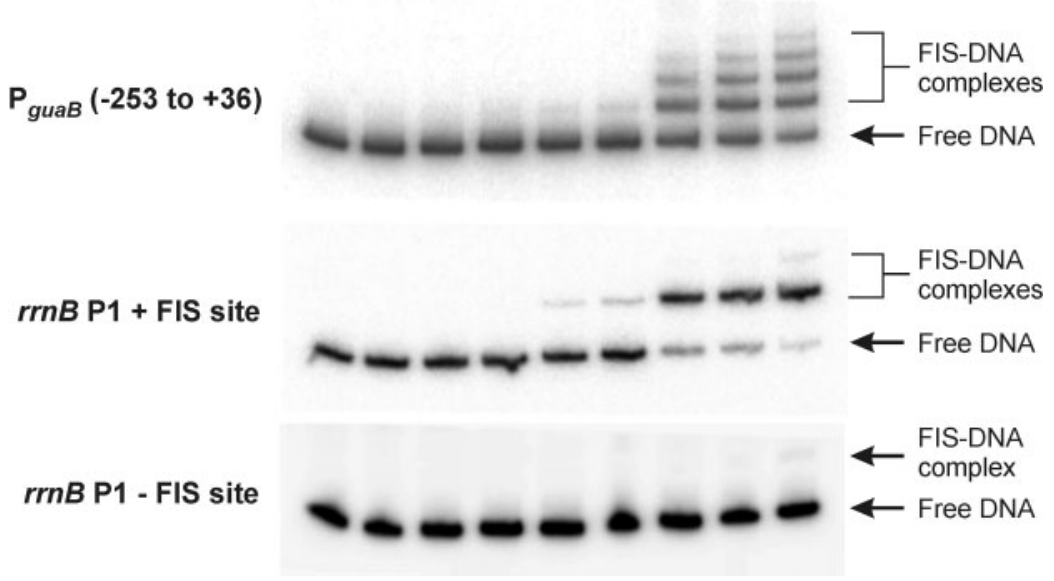

Fig. 2. Analysis of FIS binding to $P_{\text {guaB }}$ by EMSA. EMSA was employed to compare the relative binding affinity of FIS for a DNA fragment containing $P_{\text {guaB }}(-253$ to +36$)$ with an $r r n B \mathrm{P} 1$ promoter derivative containing FIS site I ('rrnB P1+FIS site') and $r r n B \mathrm{P} 1$ containing no FIS sites ('rrnB P1-FIS site'). The concentration of FIS in each binding reaction is indicated above the corresponding gel lane. 


\section{Mapping the location of FIS binding sites at $\mathbf{P}_{\text {guaB }}$ by DNase I footprinting}

To determine the location of any FIS binding sites at $\mathrm{P}_{\text {guab }}$, a DNA fragment extending from positions -253 to +36 of $\mathrm{P}_{\text {guaB }}\left[\right.$ i.e. $\mathrm{P}_{\text {guaB }}(-253$ to +36$)$ ] was radiolabelled at the downstream end, and DNase I footprinting was performed in the presence or absence of purified FIS. The results show that increasing the concentration of FIS up to $500 \mathrm{nM}$ resulted in increased protection at two sites centred near positions -11 and +8 (FIS site 1 and FIS site 2, respectively) (Fig. 3). DNA fragments corresponding to $\mathrm{P}_{\text {guab }}$ sequences downstream of position +16 were not visible on this gel. To determine whether FIS bound to sequences downstream of position +16 , a DNA fragment extending from positions -133 to +36 [i.e. $\mathrm{P}_{\text {gua }}(-133$ to +36)] was radiolabelled at the upstream end for DNase I footprinting. The results show that, in addition to the protection observed at FIS sites 1 and 2, a third site (FIS site 3 ) centred near position +29 was also bound by FIS. FIS sites 2 and 3 were identified by comparison with the consensus as being more likely to recruit FIS (i.e. FIS site 3 is a category 1 site, and FIS site 2 is a category 2 site) (Fig. 1b). However, protection of other category 1 and category 2 FIS sites that were identified by bioinformatic analysis was not observed. Interestingly, FIS site 1 contains mismatches to the consensus at two critical positions, and therefore was not identified by the bioinformatic analysis (Fig. 1b). FIS did not bind to any of the previously predicted FIS sites (FIS sites I-IV). It should be noted that another FIS site (site $2^{\prime}$ ) is located overlapping site 2, with its centre shifted by one base pair downstream of the centre of site 2 (Fig. 1). As sites that contain both an A at position -4 and $\mathrm{a} T$ at position +4 are bound by FIS much less efficiently than are sites that lack a $\mathrm{G}$ at position -7 (or a $\mathrm{C}$ at +7 ) (Shao et al., 2008), it is possible that site $2^{\prime}$ may be preferred by FIS over site 2 .

\section{Role of FIS in the regulation of transcription from $\mathbf{P}_{\text {guaB }}$ in vitro}

To determine the role of FIS in the regulation of $\mathrm{P}_{\text {gua }}$, multiple-round transcription reactions were performed in the presence or absence of $250 \mathrm{nM}$ FIS. Transcription was measured from $\mathrm{P}_{\text {gua }}(-253$ to +36$)$ and shorter derivatives $\left[\mathrm{P}_{\text {gua }}(-133\right.$ to +36$), \mathrm{P}_{\text {gua }}(-59$ to +36$)$, $\mathrm{P}_{\text {gua }}(-37$ to +36$), \mathrm{P}_{\text {guaB }}(-133$ to +21$), \mathrm{P}_{\text {gua }}(-133$ to $+1)$ and $\mathrm{P}_{\text {guaB }}(-253$ to +10$)$ ] (end points as indicated). Addition of FIS to the transcription reaction resulted in $\sim 8-10$-fold repression of transcription from $\mathrm{P}_{\text {gua }}(-253$ to +36). Under the same conditions, there was no repressive effect of FIS on transcription from the $r r n B$ P1 promoter (Fig. $4 \mathrm{a}, \mathrm{b}$ ). This indicates that the repression of $\mathrm{P}_{\text {gua }}$ afforded by FIS at a concentration of $250 \mathrm{nM}$ was due to a site-specific FIS-DNA interaction. Deletion of sequences upstream of the $\mathrm{P}_{\text {guaB }} \mathrm{UP}$ element [i.e. $\mathrm{P}_{\text {gua }}$ $(-59$ to +36$)$ ] did not lead to any significant change in the degree of repression afforded by FIS, confirming that putative FIS sites I-IV do not play a role in the regulation of $\mathrm{P}_{\text {gua }}$ by FIS. Deletion of the $\mathrm{P}_{\text {gua }}$ UP element $\left[\mathrm{P}_{\text {gua }}\right.$ $(-37$ to +36$)]$ gave rise to an undetectable level of transcripts from $\mathrm{P}_{\text {guaB }}$ in the presence of FIS, which meant that the fold repression afforded by FIS could not be

\section{$P_{\text {guaB }}(-253$ to +36$)$}

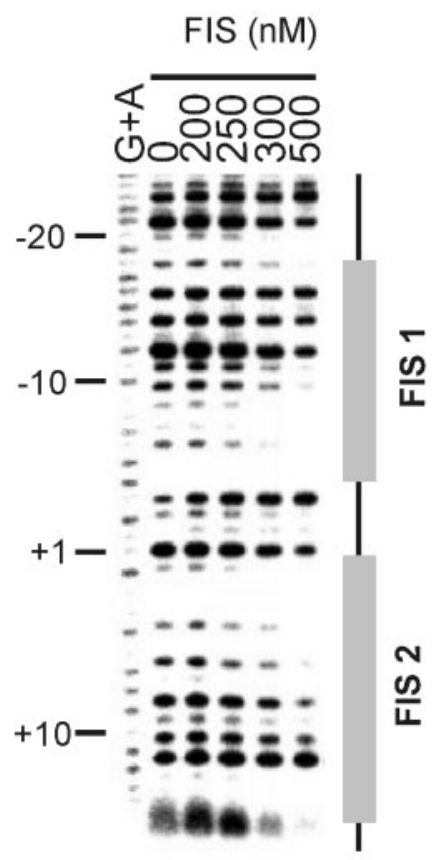

\section{$P_{\text {guaB }}(-133$ to +36$)$}

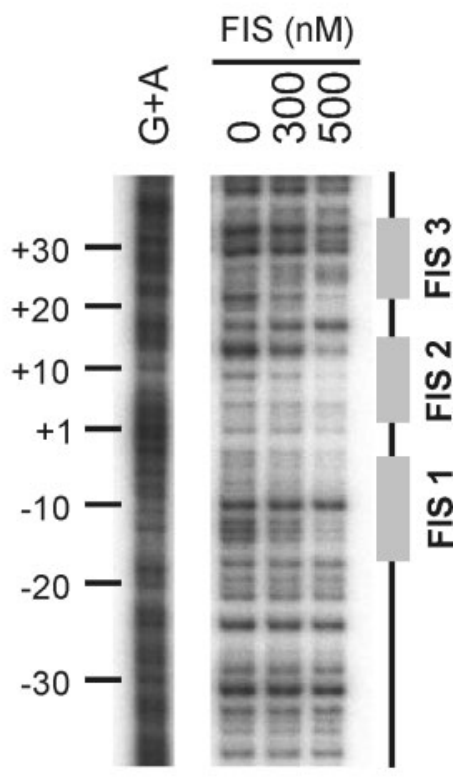

Fig. 3. Mapping the location of FIS sites at $\mathrm{P}_{\text {guaB }}$ by DNase I footprinting. A DNA fragment containing $P_{\text {gua }}(-253$ to +36$)$ radiolabelled at the downstream end (relative to the gua $B$ transcription start site), and a DNA fragment containing $\mathrm{P}_{\text {guaB }}(-133$ to +36$)$ labelled at the upstream end, were employed in DNase I footprinting in the presence of different concentrations of FIS (as shown). Nucleotide positions are shown relative to the gua $B$ transcription start site, and lanes containing the $\mathrm{G}+\mathrm{A}$ ladder are indicated accordingly. 


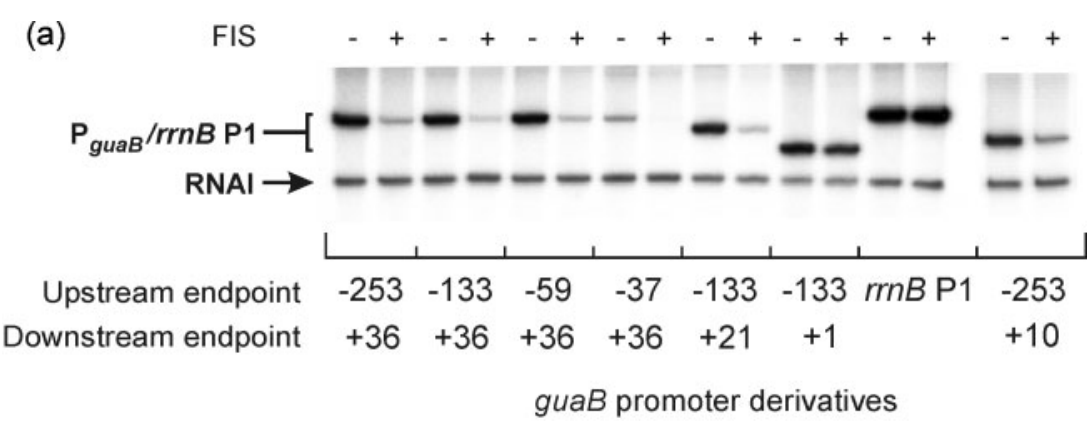

(b)

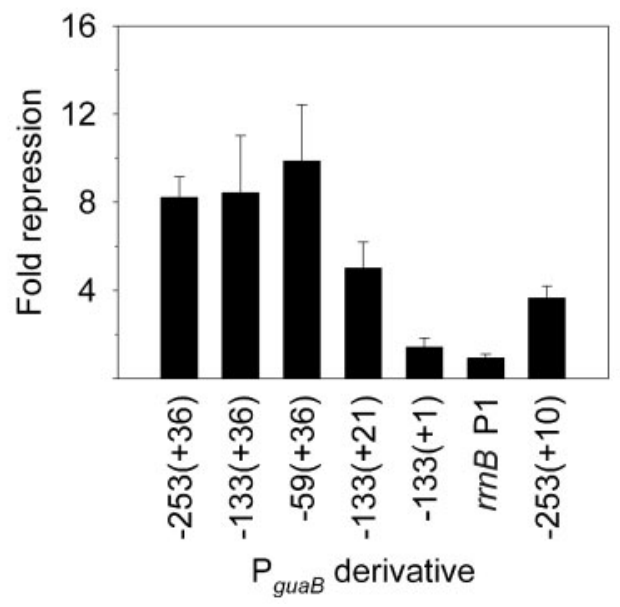

Fig. 4. Role of FIS in regulation of transcription from $\mathrm{P}_{\text {guaB }}$ in vitro. (a) Multiple-round in vitro transcription was employed to measure transcription from $\mathrm{P}_{\text {guaB }}$ derivatives $\mathrm{P}_{\text {guaB }}$ $(-253$ to +36$), P_{\text {gua }}(-133$ to +36$), P_{\text {gua }}$ $(-59$ to +36$), \mathrm{P}_{\text {gua }}(-37$ to +36$), \mathrm{P}_{\text {gua }}(-133$ to +1$), P_{\text {gua } B}(-133$ to +21$)$ and $P_{\text {gua }}(-253$ to +10$)$ in the presence $(+)$ and absence $(-)$ of $250 \mathrm{nM}$ FIS. Promoter endpoints are as indicated. $P_{\text {guaB }}(-133$ to +21$)$ lacks FIS site 3 , and $P_{\text {guaB }}(-133$ to +1$)$ lacks FIS sites 2 and 3 . As a control, transcription was also measured from an $r r n B P 1$ promoter derivative that did not contain any FIS sites. All promoters were cloned in pRLG770 and supercoiled DNA was used for the assays. The vector-encoded replication repressor, RNAI ( 110 nucleotides), is also indicated. (b) The repression afforded by FIS at each promoter is shown. The fold repression by FIS was calculated by dividing the activity in the absence of FIS by the activity in its presence. Values are the mean (with standard deviation) of three independent experiments. The activity of $\mathrm{P}_{\text {guaB }}(-37$ to +36$)$ in the presence of FIS was too low to quantitate and hence a value for the fold repression was not obtained. determined. Deletion of FIS site 3 [i.e. $\mathrm{P}_{\text {gua }}(-133$ to +21 )] led to decreased repression by FIS (approximately sixfold repression), and deletion of both FIS site 2 and FIS site 3 [i.e. $\mathrm{P}_{\text {guab }}(-133$ to +1$)$ ] gave rise to an approximately twofold repression by FIS (Fig. 4b). As $\mathrm{P}_{\text {guaB }}(-133$ to +1$)$ retains FIS site 1 and is still subject to some degree of repression by FIS, these results indicate that FIS sites 1-3 each contribute to repression of $\mathrm{P}_{\text {guaB }}$, and that FIS site 1 can function independently of the other FIS sites. A $\mathrm{P}_{\text {guab }}$ derivative harbouring a deletion of FIS site 3 and deletion of the downstream six bases of FIS site 2 [i.e. $\mathrm{P}_{\text {guas }}(-253$ to +10$)$ ] was subject to an approximately fourfold repression by FIS, indicating that FIS site 2 had not been completely inactivated (Fig. $4 \mathrm{~b}$ ).

\section{FIS is not required for growth rate-dependent control of $\mathbf{P}_{\text {gua }}$}

GRDC of $\mathrm{P}_{\text {guaB }}(-253$ to +36$)$ was measured in a wildtype strain background and in a strain that harboured a deletion in the fis gene. To determine whether FIS site 3 is important for GRDC of $\mathrm{P}_{\text {gua }}$, activity of $\mathrm{P}_{\text {guaB }}(-253$ to $+10)$ was also analysed. In exponentially growing wildtype E. coli cells, the activity of $\mathrm{P}_{\text {guaB }}(-253$ to +36$)$ increased approximately twofold with every doubling of the growth rate as, shown previously (Fig. 5a, c; Davies \& Drabble, 1996; Husnain \& Thomas, 2008). In an otherwise isogenic fis strain, the activity of $\mathrm{P}_{\text {guaB }}(-253$ to +36$)$ was higher than in the wild-type at all growth rates and was more pronounced at faster growth rates (i.e. an approximately twofold increase in activity was observed at the fastest growth rate) (Fig. 5a). However, the degree of GRDC was similar to that observed in a wild-type strain (i.e. in both cases, a doubling of the growth rate corresponded to an approximately twofold increase in promoter activity) (compare plots of relative activity versus growth rate, Fig. 5c). These results demonstrate that FIS is not required for GRDC of $\mathrm{P}_{\text {guaB }}$. Although FIS appears to downregulate transcription from $\mathrm{P}_{\text {guas }}$ in vivo, deletion of FIS site 3 and part of FIS site 2 did not lead to a significant change in $\mathrm{P}_{\text {guaB }}$ activity in exponentially growing wild-type cells in comparison to $\mathrm{P}_{\text {guab }}$ containing the full complement of functional FIS sites [i.e. a 1.87-fold increase in $\mathrm{P}_{\text {guab }}$ $(-253$ to +10$)$ activity occurred for every doubling of the growth rate in comparison to a 1.84-fold increase for $\mathrm{P}_{\text {gua }}$ $(-253$ to +36$)($ Fig. 5a, b)]. These results suggest either that FIS site 1 is able to effect full repression in vivo (contrasting with the results obtained in vitro) or that FIS sites 1-3 may not contribute to repression of $\mathrm{P}_{\text {guab }}$ in vivo under the conditions employed, and therefore the observed FISdependent repression is indirect.

\section{FIS is not required for growth phase-dependent regulation of $\mathbf{P}_{\text {gua }}$}

Previous studies indicate that FIS levels are elevated during the mid-exponential growth phase, and they decrease sharply as cells enter stationary phase (Appleman et al., 
(a)

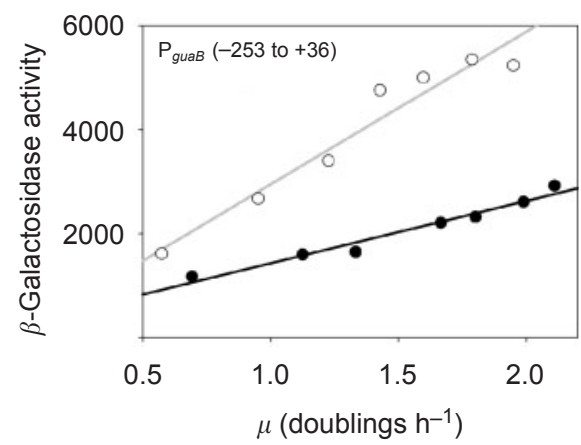

(b)

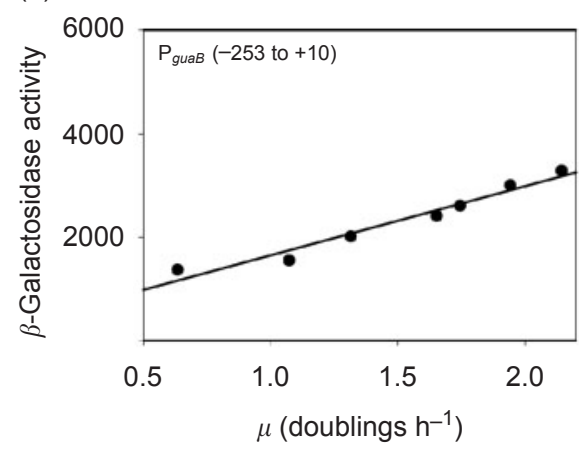

(c)

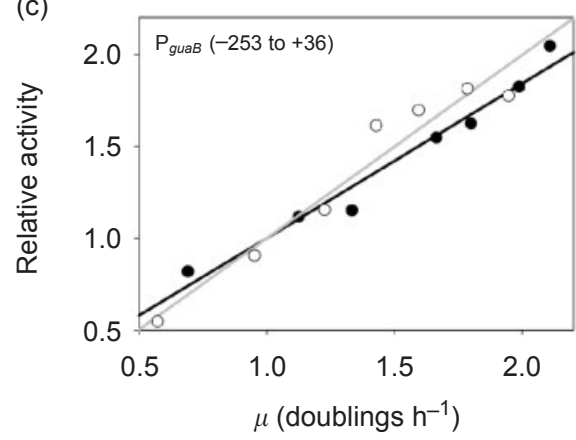

Fig. 5. GRDC of $\mathrm{P}_{\text {guaB }}$. $(\mathrm{a}, \mathrm{c}) \mathrm{GRDC}$ of a wild-type strain $(\mathbf{\bullet})$ or a strain containing the fis : $\operatorname{aad} A$ allele $(\bigcirc)$, harbouring a fusion of $\mathrm{P}_{\text {guaB }}(-253$ to +36 ) to lacZ, was analysed. (b) GRDC of a wildtype strain harbouring a $\mathrm{P}_{\text {gua }}(-253$ to +10$)$-lac $Z$ fusion was also measured. Strains were grown at different cellular growth rates to an $\mathrm{OD}_{600}$ of $0.34-0.45$, whereupon the $\beta$-galactosidase activity was determined. The promoter activity for $\mathrm{P}_{\text {guaB }}(-253$ to +36$)$ in the presence and absence of functional fis is given both in Miller units ( $\beta$-galactosidase activity) and expressed as a ratio to the activity at 1 doubling per hour (relative activity). The magnitude of the gradient in plots of relative promoter activity versus doublings per hour is proportional to the degree of GRDC. Each data point represents the mean promoter activity or mean growth rate. The mean was calculated using data obtained from three independent experiments.

1998). This phenomenon is responsible for the known contribution of FIS to growth-phase-dependent regulation of some promoters (Nilsson et al., 1992; Appleman et al.,
1998; Mallik et al., 2006; Bradley et al., 2007). To test whether FIS-dependent regulation of $\mathrm{P}_{\text {guab }}$ varies with the growth phase, transcription from a $\mathrm{P}_{\text {guab }}$ derivative with an upstream end point of -69 that contained all three experimentally determined FIS sites [i.e. $\mathrm{P}_{\text {gua }}(-69$ to +36)] was measured at different stages of growth in a wildtype strain, and in a strain that harboured a deletion in the fis gene. This promoter derivative was chosen as it lacks the putative CRP site centred near position -117.5 (Hutchings \& Drabble, 2000). It has previously been shown that FIS represses the crp1 promoter and this may alter cellular levels of CRP (Gonzalez-Gil et al., 1998).

In accordance with the results of the GRDC experiment, the activity of $\mathrm{P}_{\text {guas }}$ was higher in the fis background than in the wild-type strain throughout the course of the growth cycle. In the wild-type strain, $\mathrm{P}_{\text {guaB }}$ activity increased by nearly $40 \%$ as cells entered the mid-exponential growth phase (i.e. the promoter activity at an $\mathrm{OD}_{600}$ of $\sim 0.15-0.20$ was $40 \%$ higher than the activity at an $\mathrm{OD}_{600}$ of $\sim 0.012$ ). The increase in activity in a fis strain over the corresponding part of the growth curve was less marked (i.e. there was a $\sim 16 \%$ increase in promoter activity). Upon entry into stationary phase, there was a gradual decrease in the promoter activity in both strain backgrounds (Fig. 6). The results suggest that $\mathrm{P}_{\text {guaB }}$ is subject to a degree of growthphase-dependent regulation. However, there was no significant change in the transcription activity profile during the growth cycle when comparing the two strain

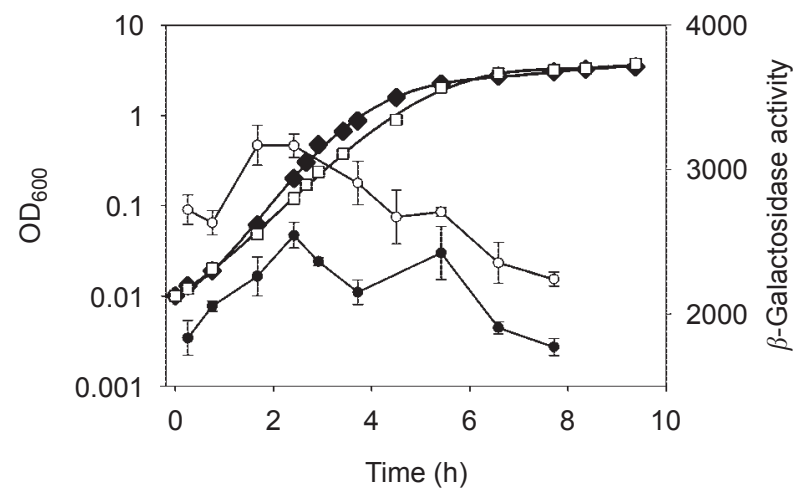

Fig. 6. Growth-phase-dependent regulation of $P_{\text {guaB }}$. A wild-type strain or a strain containing the fis::aadA allele ( $\Delta$ fis), each harbouring a fusion of $P_{\text {guaB }}(-69$ to +36$)$ to lac $Z$, were inoculated from a dense culture into fresh growth medium [M9 minimal medium containing $0.4 \%(\mathrm{w} / \mathrm{v})$ glucose, $0.8 \%(\mathrm{w} / \mathrm{v})$ Casamino acids and $5 \mu \mathrm{g}$ thiamine $\mathrm{ml}^{-1}$ ] to an $\mathrm{OD}_{600}$ of $\sim 0.01$. Samples were taken during different stages of growth and the $\beta$ galactosidase activity was determined. The promoter activity of the wild-type strain ( $\bullet$ ) and $\Delta$ fis strain $(\bigcirc)$ is given in Miller units $(\beta$ galactosidase activity). Values presented are the mean $\pm S D$, for three independent experiments. Cell density measurements $\left(O D_{600}\right)$ for single cultures that are representative of the growth curve for the wild-type strain $(\Delta)$ and the $\Delta$ fis strain $(\square)$, were plotted on a logarithmic axis. 
backgrounds. Furthermore, $\mathrm{P}_{\text {guaB }}$ activity peaks at the time that FIS levels are expected to be at their highest, and then falls off upon entry into stationary phase when FIS levels fall (Appleman et al., 1998; Ali Azam et al., 1999). These observations suggest that FIS does not significantly influence growth phase-dependent regulation of $\mathrm{P}_{\text {guaB }}$ under the conditions employed.

\section{DISCUSSION}

A previous study identified four adjacent putative FIS binding sites (FIS sites I-IV) located upstream of the UP element at $\mathrm{P}_{\text {guaB }}$. These sites were identified by comparison of the upstream $\mathrm{P}_{\text {guaB }}$ sequence to a published consensus sequence for FIS (Finkel \& Johnson, 1992, Hutchings \& Drabble, 2000). By employing sequence alignment to compare $\mathrm{P}_{\text {gua }}$ sequences to a more representative consensus for FIS, we have identified four candidate FIS sites that bear a closer resemblance to this consensus than FIS sites I-IV (Ross et al., 1999). Two of these sites, sites 2 (or $2^{\prime}$ ) and 3 (centred near positions +8 and +29 relative to the guaB transcription start site, respectively), are protected by FIS in DNase I footprinting experiments. One of the other two candidate FIS sites overlaps the UP element, and the remaining site is located at a distance upstream of the core promoter elements (centred at -213). Neither of these sites recruits FIS as judged by DNase I footprinting. Putative FIS sites I-IV also do not bind FIS. Interestingly, we show that a site centred at position -11 , which was not identified as a likely FIS site, also recruits FIS. This suggests that although bioinformatic analyses are useful when searching for sites that are bound by FIS, they may not be useful in identifying some FIS binding sites that exhibit a weak match to the consensus.

At the tyrT promoter, FIS binding to sites II and III (centred at positions -91 and -122 , respectively) cooperatively affects the binding of FIS to site I centred at -71 bp upstream of the transcription start site (Lazarus \& Travers, 1993; Pemberton et al., 2002). As the B-form of DNA has a periodicity of $10.6 \mathrm{bp}$, this places these three sites on the same face of the DNA helix, with the centres of sites I and II separated by $21 \mathrm{bp}$. This suggests that cooperative interactions require adjacent FIS dimers to be positioned on the same face of the DNA, two turns of the DNA helix apart. At the $r r n B$ P1 promoter, FIS sites I-III are centred at positions $-71,-102$ and -143 , respectively, also placing them approximately on the same face of the DNA helix. However, FIS does not bind to $r r n B$ P1 cooperatively in the absence of RNAP, and it is noteworthy that the central positions of these sites are separated by 32 or $42 \mathrm{bp}$ (i.e. not $21 \mathrm{bp}$ ). Interestingly, at $\mathrm{P}_{\text {gua }}$, FIS sites 2 and 3 are positioned 22 bp apart (centre to centre) which will also place them on the same face of the DNA helix and a similar distance apart as FIS sites I and II at the tyrT promoter. However, the centres of FIS sites 1 and 2 at $\mathrm{P}_{\text {gua }}$ are $18 \mathrm{bp}$ apart, making it unlikely that they are located on the same face of the DNA. Therefore, it is possible that FIS binds cooperatively to sites 2 and 3, but it appears less likely that occupancy of sites 2 and/or 3 stimulates binding of FIS to site 1.

Consistent with the location of functional FIS sites, we show that FIS represses transcription from $\mathrm{P}_{\text {gua }} \sim 8-10$ fold in vitro. Deletion of FIS site 3 results in partial relief of repression, and deletion of FIS sites 2 and 3 together further relieves repression in vitro. The residual FISmediated repression of the guaB promoter fragment containing the +1 downstream end point is likely to occur through interactions with site 1 , and would suggest that binding of to site 1 does not require cooperative interactions with FIS dimers bound to adjacent sites. The binding of FIS to site 1 is likely to sterically hinder the recruitment of RNAP to $\mathrm{P}_{\text {guaB }}$, as observed at the crpl promoter (Gonzalez-Gil et al., 1998). The role of FIS sites 2 and 3, which together exert the most influence on transcription from $\mathrm{P}_{\text {guaB }}$ in vitro, is less clear, although it is likely that the role of FIS site 3 is to stimulate binding of FIS to site 2, which in turn may play more of a direct role in repression. Our results suggest that the presence of FIS should decrease RNAP binding to $\mathrm{P}_{\text {gua }}$. However, DNase I footprinting experiments carried out in the presence of both FIS and RNAP were inconclusive (data not shown).

Although our results demonstrate that FIS represses transcription from $\mathrm{P}_{\text {gua }}$ in vitro, evidence for direct repression by FIS in vivo was not obtained (i.e. deletion of FIS sites 2 and 3 did not result in increased $\mathrm{P}_{\text {guaB }}$ activity in wild-type exponentially growing cells). This is consistent with the results of a chromatin immunoprecipitation (ChIP)-chip analysis carried out under similar conditions, in which FIS binding at $\mathrm{P}_{\text {gua }}$ was not detected (see supplementary data in Grainger et al., 2006). However, in a fis strain we observed an increase in the activity of the guaB promoter in derivatives containing all three FIS sites in the presence $\left(\mathrm{P}_{\text {gua }}(-253\right.$ to +36$\left.)\right)$ or absence $\left[\mathrm{P}_{\text {gua }}(-69\right.$ to $+36)]$ of the putative CRP site centred at -117.5 . This rules out the possibility that the effect of deleting fis on guaB promoter activity is mediated by changes in CRP abundance [FIS has been shown to modulate transcription of crp (Gonzalez-Gil et al., 1998)]. However, it is possible that the change in transcription activity of $\mathrm{P}_{\text {guab }}$ in a fis background occurs as a result of altered regulation of $\mathrm{P}_{\text {guaB }}$ by a transcription factor other than CRP, for example $\mathrm{H}$ NS or HU (Claret \& Rouviere-Yaniv, 1996; Falconi et al., 1996) or by changes in supercoiling (Schneider et al., 1997; Weinstein-Fischer et al., 2000). Another possible explanation is that the potential relief of $\mathrm{P}_{\text {guaB }}$ repression that occurs upon deleting FIS sites 2 and 3 is masked in vivo through an alternative compensatory regulatory mechanism. A less likely explanation, in view of the poor match to the consensus FIS binding site, is that FIS binding to site 1 mediates full FIS-mediated repression in vivo.

A previous study has shown that the $\mathrm{P}_{\text {gua }} \mathrm{UP}$ element, and sequences located further upstream, are required for GRDC of $\mathrm{P}_{\text {guaB }}$ (Husnain \& Thomas, 2008). Our results show that 
FIS does not play a role in GRDC at this promoter, thereby implying that a different cellular factor is required for conferring GRDC on $\mathrm{P}_{\text {gua }}$ (Emilsson \& Nilsson, 1995; Dennis et al., 2004; Paul et al., 2004). Experiments are under way to uncover the identity of this factor(s). Our results also suggest that $\mathrm{P}_{\text {guaB }}$ is subject to growth phasedependent control. However, although levels of FIS protein are also subject to growth phase-dependent control, it does not appear to play an important role in growth phasedependent control at $\mathrm{P}_{\text {guaB }}$. Thus, the physiological role of FIS at the guaB promoter remains to be elucidated.

\section{ACKNOWLEDGEMENTS}

This work was supported by a family $\mathrm{PhD}$ sponsorship awarded to S. I. H., kindly provided by S. M. Husnain, and a research project grant awarded to M.S. T. by the Wellcome Trust (grant ref. 073917). We thank W. Ross, T. Gaal, H. Murray and R. L. Gourse (University of Wisconsin-Madison) for strains, plasmids and purified FIS protein. We are grateful to T. Belyaeva (University of Leeds) for advice on EMSA, and also to S. J. W. Busby and D. Browning (University of Birmingham) for strains and advice on DNase I footprinting.

\section{REFERENCES}

Aiyar, S. E., McLeod, S. M., Ross, W., Hirvonen, C. A., Thomas, M. S., Johnson, R. C. \& Gourse, R. L. (2002). Architecture of Fis-activated transcription complexes at the Escherichia coli $\mathrm{rrnB}$ P1 and $\mathrm{rrnE}$ P1 promoters. J Mol Biol 316, 501-516.

Ali Azam, T., Iwata, A., Nishimura, A., Ueda, S. \& Ishihama, A. (1999). Growth phase-dependent variation in protein composition of the Escherichia coli nucleoid. J Bacteriol 181, 6361-6370.

Appleman, J. A., Ross, W., Salomon, J. \& Gourse, R. L. (1998). Activation of Escherichia coli rRNA transcription by FIS during a growth cycle. J Bacteriol 180, 1525-1532.

Ball, C. A., Osuna, R., Ferguson, K. C. \& Johnson, R. C. (1992). Dramatic changes in Fis levels upon nutrient upshift in Escherichia coli. J Bacteriol 174, 8043-8056.

Bokal, A. J., Ross, W. \& Gourse, R. L. (1995). The transcriptional activator protein FIS: DNA interactions and cooperative interactions with RNA polymerase at the Escherichia coli $\mathrm{rrnB} \mathrm{P} 1$ promoter. J Mol Biol 245, 197-207.

Bradley, M. D., Beach, M. B., de Koning, A. P., Pratt, T. S. \& Osuna, R. (2007). Effects of FIS on Escherichia coli gene expression during different growth stages. Microbiology 153, 2922-2940.

Browning, D. F., Cole, J. A. \& Busby, S. J. (2000). Suppression of FNR-dependent transcription activation at the Escherichia coli nir promoter by Fis, IHF and H-NS: modulation of transcription initiation by a complex nucleo-protein assembly. Mol Microbiol 37, 1258-1269.

Browning, D. F., Beatty, C. M., Sanstad, E. A., Gunn, K. E., Busby, S. J. W. \& Wolfe, A. J. (2004). Modulation of CRP-dependent transcription at the Escherichia coli acsP2 promoter by nucleoprotein complexes: anti-activation by the nucleoid proteins FIS and IHF. Mol Microbiol 51, 241-254.

Claret, L. \& Rouviere-Yaniv, J. (1996). Regulation of HU alpha and HU beta by CRP and FIS in Escherichia coli. J Mol Biol 263, 126-139.
Davies, I. J. \& Drabble, W. T. (1996). Stringent and growth-ratedependent control of the gua operon of Escherichia coli K-12. Microbiology 142, 2429-2437.

Dennis, P. P., Ehrenberg, M. \& Bremer, H. (2004). Control of rRNA synthesis in Escherichia coli: a systems biology approach. Microbiol Mol Biol Rev 68, 639-668.

Dong, H., Kirsebom, L. A. \& Nilsson, L. (1996). Growth rate regulation of $4.5 \mathrm{~S}$ RNA and M1 RNA the catalytic subunit of Escherichia coli RNase P. J Mol Biol 261, 303-308.

Emilsson, V. \& Nilsson, L. (1995). Factor for inversion stimulationdependent growth rate regulation of serine and threonine tRNA species. J Biol Chem 270, 16610-16614.

Estrem, S. T., Gaal, T., Ross, W. \& Gourse, R. L. (1998). Identification of an UP element consensus sequence for bacterial promoters. Proc Natl Acad Sci U S A 95, 9761-9766.

Falconi, M., Brandi, A., La Teana, A., Gualerzi, C. O. \& Pon, C. L. (1996). Antagonistic involvement of FIS and H-NS proteins in the transcriptional control of hns expression. Mol Microbiol 19, 965-975.

Finkel, S. E. \& Johnson, R. C. (1992). The Fis protein: it's not just for DNA inversion anymore. Mol Microbiol 6, 3257-3265.

Gonzalez-Gil, G., Kahmann, R. \& Muskhelishvili, G. (1998). Regulation of crp transcription by oscillation between distinct nucleoprotein complexes. EMBO J 17, 2877-2885.

Gourse, R. L., Gaal, T., Bartlett, M. S., Appleman, J. A. \& Ross, W. (1996). rRNA transcription and growth rate-dependent regulation of ribosome synthesis in Escherichia coli. Annu Rev Microbiol 50, 645677.

Grainger, D. C., Hurd, D., Goldberg, M. D. \& Busby, S. J. W. (2006). Association of nucleiod proteins with coding and non-coding segments of the Escherichia coli genome. Nucleic Acids Res 34, 4642-4652.

Hengen, P. N., Bartram, S. L., Stewart, L. E. \& Schneider, T. D. (1997). Information analysis of Fis binding sites. Nucleic Acids Res 25, 4994-5002.

Husnain, S. I. \& Thomas, M. S. (2008). The UP element is necessary but not sufficient for growth rate-dependent control of the Escherichia coli guaB promoter. J Bacteriol 190, 2450-2457.

Hutchings, M. I. \& Drabble, W. T. (2000). Regulation of the divergent guaBA and xseA promoters of Escherichia coli by the cyclic AMP receptor protein. FEMS Microbiol Lett 187, 115-122.

Jackson, L., Blake, T. \& Green, J. (2004). Regulation of $n d h$ expression in Escherichia coli by Fis. Microbiology 150, 407-413.

Lazarus, L. R. \& Travers, A. A. (1993). The Escherichia coli FIS protein is not required for the activation of $\operatorname{tyr} T$ transcription on entry into exponential growth. EMBO J 12, 2483-2494.

Mallik, P., Paul, B. J., Rutherford, S. T., Gourse, R. L. \& Osuna, R. (2006). DksA is required for growth phase-dependent regulation, growth rate-dependent control, and stringent control of fis expression in Escherichia coli. J Bacteriol 188, 5775-5782.

McLeod, S. M., Aiyar, S. E., Gourse, R. L. \& Johnson, R. C. (2002). The C-terminal domains of the RNA polymerase $\alpha$ subunits: contact site with Fis and localization during co-activation with CRP at the Escherichia coli proP P2 promoter. J Mol Biol 316, 517-529.

Mehra, R. K. \& Drabble, W. T. (1981). Dual control of the gua operon of Escherichia coli K12 by adenine and guanine nucleotides. J Gen Microbiol 123, 27-37.

Meng, L. M., Kilstrup, M. \& Nygaard, P. (1990). Autoregulation of PurR repressor synthesis and involvement of purR in the regulation of purB, purC, purL, purMN and guaBA expression in Escherichia coli. Eur J Biochem 187, 373-379. 
Meng, W., Savery, N. J., Busby, S. J. W. \& Thomas, M. S. (2000). The Escherichia coli RNA polymerase $\alpha$ subunit linker: length requirements for transcription activation at CRP-dependent promoters. EMBO J 19, 1555-1566.

Meng, W., Belyaeva, T., Savery, N. J., Busby, S. J., Ross, W. E., Gaal, T., Gourse, R. L. \& Thomas, M. S. (2001). UP element-dependent transcription at the Escherichia coli $\mathrm{rrnB}$ P1 promoter: positional requirements and role of the RNA polymerase alpha subunit linker. Nucleic Acids Res 29, 4166-4178.

Miller, J. (1972). Experiments in Molecular Genetics. Cold Spring Harbor, NY: Cold Spring Harbor Laboratory.

Newlands, J. T., Ross, W., Gosink, K. K. \& Gourse, R. L. (1991). Factor-independent activation of Escherichia coli rRNA transcription. II. characterization of complexes of $r r n B$ P1 promoters containing or lacking the upstream activator region with Escherichia coli RNA polymerase. J Mol Biol 220, 569-583.

Nilsson, L., Verbeek, H., Vijgenboom, E., van-Drunen, C., Vanet, A. \& Bosch, L. (1992). FIS-dependent trans activation of stable RNA operons of Escherichia coli under various growth conditions. J Bacteriol 174, 921-929.

Paul, B. J., Ross, W., Gaal, T. \& Gourse, R. L. (2004). rRNA transcription in Escherichia coli. Annu Rev Genet 38, 749-770.

Pemberton, I. K., Muskhelishvili, G., Travers, A. A. \& Buckle, M. (2002). FIS modulates the kinetics of successive interactions of RNA polymerase with the core and upstream regions of the tyrT promoter. J Mol Biol 318, 651-663.

Quandt, K., Frech, K., Karas, H., Wingender, E. \& Werner, T. (1995). MatInd and MatInspector: new fast and versatile tools for detection of consensus matches in nucleotide sequence data. Nucleic Acids Res 23, 4878-4884.

Rao, L., Ross, W., Appleman, J. A., Gaal, T., Leirmo, S., Schlax, P. J., Record, M. T., Jr \& Gourse, R. L. (1994). Factor independent activation of $r r n B$ P1. An "extended" promoter with an upstream element that dramatically increases promoter strength. J Mol Biol 235, 1421-1435.

Ross, W., Thompson, J. F., Newlands, J. T. \& Gourse, R. L. (1990). Escherichia coli Fis protein activates ribosomal RNA transcription in vitro and in vivo. EMBO J 9, 3733-3742.
Ross, W., Aiyar, S. E., Salomon, J. \& Gourse, R. L. (1998). Escherichia coli promoters with UP elements of different strengths: modular structure of bacterial promoters. J Bacteriol 180, 5375-5383.

Ross, W., Salomon, J., Holmes, W. M. \& Gourse, R. L. (1999). Activation of Escherichia coli leuV transcription by FIS. J Bacteriol 181, 3864-3868.

Schneider, R., Travers, A. \& Muskhelishvili, G. (1997). FIS modulates growth phase-dependent topological transitions of DNA in Escherichia coli. Mol Microbiol 26, 519-530.

Shao, Y., Feldman-Cohen, L. S. \& Osuna, R. (2008). Functional characterisation of the Escherichia coli Fis-DNA binding sequence. J Mol Biol 376, 771-785.

Shultzaberger, R. K., Roberts, L. R., Lyakhov, I. G., Sidorov, I. A., Stephen, A. G., Fisher, R. J. \& Schneider, T. D. (2007). Correlation between binding rate constants and individual information of E. coli Fis binding sites. Nucleic Acids Res 35, 5275-5283.

Simons, R. W., Houman, F. \& Kleckner, N. (1987). Improved single and multicopy lac-based cloning vectors for protein and operon fusions. Gene 53, 85-96.

Tesfa-Selase, F. \& Drabble, W. T. (1996). Specific binding of DnaA protein to a DnaA box in the guaB gene of Escherichia coli K12. Eur J Biochem 241, 411-416.

Tiedeman, A. A. \& Smith, J. M. (1984). Isolation and characterization of regulatory mutations affecting the expression of the guaBA operon of Escherichia coli K-12. Mol Gen Genet 195, 77-82.

Travers, A., Schneider, R. \& Muskhelishvili, G. (2001). DNA supercoiling and transcription in Escherichia coli: the FIS connection. Biochimie 83, 213-217.

Weinstein-Fischer, D., Elgrably-Weiss, M. \& Altuvia, S. (2000). Escherichia coli response to hydrogen peroxide: a role for DNA supercoiling, topoisomerase I and Fis. Mol Microbiol 35, 1413-1420.

Wu, H., Tyson, K. L., Cole, J. A. \& Busby, S. J. W. (1998). Regulation of transcription initiation at the Escherichia coli nir operon promoter: a new mechanism to account for co-dependence on two transcription factors. Mol Microbiol 27, 493-505.

Edited by: L. S. Frost 